\title{
EYE-HAND PREFERENCE IN SCHIZOPHRENIA: SEX DIFFERENCES AND SIGNIFICANCE FOR HAND FUNCTION ${ }^{1,2}$
}

\author{
YI-CHIA LIU AND YEN KUANG YANG
}

\author{
Department of Psychiatry \\ National Cheng Kung University Medical College and Hospital \\ Tainan, Taiwan
}

\section{KEH-CHUNG LIN}

Department of Rebabilitation

National Taiwan University Hospital, Taipei, Taiwan

School of Occupational Therapy

National Taiwan University College of Medicine

\section{KEITH J JEFFRIES}

National Institute on Deafness and Other Communication Disorders

National Institutes of Health

\section{HUI LEE}

Department of Psychiatry

National Cheng Kung University Medical College and Hospital, Tainan, Taiwan

\section{LI-CHING LEE}

Department of Epidemiology School of Public Health

Johns Hopkins University

Summary.-Hand preference and eye dominance were investigated in 73 (30 women, 43 men) schizophrenic patients and 71 ( 30 women, 41 men) healthy controls. There were significantly more schizophrenic patients and normal controls who were significantly right-hand dominant. However, schizophrenic patients showed a significant excess of left-eye dominance relative to controls $(65.8 \%$ vs $29.6 \%$; Odds Ratio $=$ $4.75, p<.001)$. In addition, female schizophrenic patients showed a higher rate of nonright (either left or inconsistent) eye dominance $(80 \%)$ than male schizophrenic patients $(55.8 \%)$ and controls $(33.3 \%)$. Analysis of hand performance on the Purdue Pegboard Test indicated that schizophrenic patients who showed crossed eye-hand dominance scored higher than did patients without crossed eye-hand dominance.

There is evidence for an anomaly in the lateralization process in schizophrenia (Crow, 1990). Left hemispheric dysfunction has been suggested to be related to the disorder (Gur, 1977; Donnelly, 1984; Lobel, Swanda, \& Losonczy, 1994). In particular, Crow, Colter, Frith, Johnstone, and Owena (1989) proposed that schizophrenia may be related to an anomaly of the right-shift gene (or cerebral dominance gene), which is thought to control

\footnotetext{
${ }^{1}$ The authors thank Mr. Chih Ming Tsai, Dr. Tzung Lieh Yeh and Dr. Chwen Cheng Chen from the Department of Psychiatry, National Cheng Kung University Medical College and Hospital and Ms. Hsin-mei Chen from School of Occupational Therapy, National Taiwan University College of Medicine for their statistical and editorial assistance in the preparation of this manuscript.

${ }^{2}$ Address correspondence to Dr. Keh-chung Lin, Department of Rehabilitation, National Taiwan University Hospital, 7 Chung-shan South Rd., Taipei, Taiwan or e-mail (kclin@ha.mc.ntu. edu.tw).
} 
cerebral asymmetries. In support of this, some previous reports noted the greater frequency of left-eye dominance among schizophrenic patients than normal people (Oddy \& Lobstein, 1972; Piran, Bigler, \& Cohen, 1982; Merrin, 1984; Yan, Flor-Henry, Chen, Li, Qi, \& Ma, 1985; Gureje, 1988; Cannon, Jones, Murray, \& Wadsworth, 1997), although one earlier study also reported an excess of right-eye dominance in a sample of schizophrenic patients (Kameyama, Niwa, Hiramatsu, \& Saitoh, 1983). With respect to hand preference, most of the literature strongly supports the view that schizophrenia is either associated with an atypical left shift in the handedness or a higher frequency of mixed-handedness (Carlsson, Hugdahl, Uvebrant, Wiklund, \& Wendt, 1992; Cannon, Bryne, Cassidy, Larkin, Horgan, Sheppard, \& O'Callaghan, 1995; Orr, Cannon, Gilvarry, Jones, \& Murray, 1999; Satz \& Green, 1999). However, according to Yan, et al.'s report (1985), in which all of the subjects were recruited from the Chinese community, there was a nonsignificant trend toward increasing sinistrality in schizophrenics.

Previous studies have demonstrated there are laterality (hand preference and eye dominance) differences between schizophrenic patients and normal controls. Subjects were tested by handedness and eye-dominance questionnaires (Piran, et al., 1982; Cannon, et al., 1997). Cross-dominance is much more common in male schizophrenic patients (Lobel, et al., 1994), but the results cannot be generalized for all men and women. To understand the discrepancies in previous literature, this study examined: (1) the difference in eye and hand dominance between schizophrenic patients and normal controls, using the Edinburgh Handedness Inventory and the Hole-in-the-Hand technique; (2) the sex effect; and (3) the functional significance of eye-hand preference in schizophrenics using the Purdue Pegboard Test to compare dexterity between individuals with crossed eye-hand dominance, i.e., left eye with right hand, and those with a consistent pattern of eye-hand dominance.

Method

\section{Subjects}

Seventy-three patients ( 30 women, 43 men) between the ages of 17 to 59 meeting DSM-IV (American Psychiatric Association, 1994) diagnostic criteria for schizophrenia were recruited for the study. The mean age of the 43 men was 31.9 yr. $(S D=7.6)$ and of 30 women was 32.3 yr. $(S D=9.2)$. Those who had a history of substance abuse, mental retardation, neurological illness, major medical illness that affected brain functions or head injury with loss of consciousness or who had received electroconvulsive therapy in the past two years were excluded given concerns that these factors might confound the results of neuropsychological tests.

Seventy-one healthy volunteers ( 30 women, 41 men) were also recruited 
from the community by advertisement and were interviewed by a senior psychiatrist using the Chinese version of the Mini International Neuropsychiatric Interview (Sheehan, Lecrubier, Sheehan, Amorim, Janavs, Weiller, Hergueta, Baker, \& Dunbar, 1998) to exclude the possibility of mental illness. All of these individuals were recruited from Taiwan and therefore are ethnic Chinese. Those who had a history of psychiatric illness or substance abuse or a family history of psychiatric illness were excluded from this study. The demographic characteristics of the subjects are shown in Table 1. Before the study began, informed consent was obtained from volunteers themselves and from patients and their key caregivers. The Ethical Committee for Human Research, National Cheng Kung University Medical Center, had approved the study protocol.

TABLE 1

Demographic and Clinical Characteristics of Patients and Demographically Matched Normal Controls

\begin{tabular}{|c|c|c|c|c|c|c|c|c|}
\hline & \multicolumn{4}{|c|}{ Schizophrenic Patients } & \multicolumn{4}{|c|}{ Controls } \\
\hline & \multicolumn{2}{|c|}{ Women } & \multicolumn{2}{|c|}{ Men } & \multicolumn{2}{|c|}{ Women } & \multicolumn{2}{|c|}{ Men } \\
\hline & $M$ & $S D$ & $M$ & $S D$ & $M$ & $S D$ & $M$ & $S D$ \\
\hline Age, yr. & 32.3 & 9.2 & 31.9 & 7.6 & 33.7 & 8.4 & 35.0 & 9.5 \\
\hline Education, yr. & 12.1 & 2.9 & 12.1 & 2.4 & 13.0 & 2.3 & 13.4 & 2.7 \\
\hline Age at onset of illness, yr. & 24.2 & 7.1 & 25.0 & 7.1 & & & & \\
\hline Duration of illness, yr. & 8.9 & 8.0 & 6.3 & 5.2 & & & & \\
\hline $\begin{array}{l}\text { Chlorpromazine } \\
\text { equivalents, } \mathrm{mg}\end{array}$ & 366.31 & 184.62 & 403.23 & 279.56 & & & & \\
\hline $\begin{array}{l}\text { Brief Psychiatric Rating } \\
\text { Scale Total }^{\mathrm{a}}\end{array}$ & 13.73 & 5.00 & 11.89 & 6.36 & & & & \\
\hline Handedness score & 85.8 & 18.2 & 84.9 & 20.0 & 86.6 & 15.4 & 74.9 & 24.8 \\
\hline $\begin{array}{l}\text { Eye dominance (left or } \\
\quad \text { inconsistent), } n(\%)\end{array}$ & 24 & $(80)$ & 24 & $(55.8)$ & 10 & 33.3 & 11 & 26.8 \\
\hline
\end{tabular}

${ }^{a}$ Overall and Gorham, 1962.

\section{Test Procedure}

Patients were examined when they were not in an acute condition. Three functional laterality tests were performed in this study.

Edinburgh Handedness Inventory (Oldfield, 1971).- This is a self-administered questionnaire of hand preference, in which participants are asked to indicate how they perform each of the following 10 tasks: writing, drawing, throwing, using scissors, holding a toothbrush, using a knife, using a spoon, holding a broom, striking a match, and opening a box. The subjects were asked about their preference for the right or left hand, and their scores were recorded as either weak ( 1 point) or strong ( 2 points) preference for each task. Laterality Quotients were computed as the total number of righthanded preference minus the total number of left-handed preference divided by the total number of responses, multiplied by 100 , as $(R-L / R+L) \cdot 100$. 
Hole-in-the-Hand Technique (Robison, Block, Boudreaux, \& Flora, 1999).- The dominant eye is defined as the eye whose input is favored in behavioral coordination in which only one eye can be used (Porac \& Coren, 1976). In this test, the arms are fully extended, hands placed together with palms facing away, and a small opening about the size of a quarter is made between the junctions of the thumbs and forefingers. The subjects were asked to perform the viewing, through the hole with both eyes open, five times. If the subject used the right hand in all trials, it was recorded as right-eye preference. If the subject used the right or left eye in an inconsistent manner, it was recorded as inconsistent eye preference. If the subject used the left eye in all trials, it was recorded as left eye preference.

Purdue Pegboard Manual Test (Tiffin \& Asher, 1948).-The Purdue Pegboard Test consists of a wooden board divided into two rows of 25 holes. Pegs are located in small bins on the extreme right and left sides of the board. Subjects were asked to insert pegs into the holes during a 30-sec. period with the preferred hand and then with the nonpreferred hand.

Statistical Analysis

Data analysis was carried out using the SPSS computer package (SPSS Inc., Chicago, IL). To compare both continuous and dichotomous covariates between the patient and control groups, Mann-Whitney $U$ tests (two-tailed) or chi-square tests were used. Multivariate logistic regression was performed to examine the differences in hand dominance, eye dominance and sex between schizophrenics and controls. Odds Ratios (OR) and 95\% Confidence Intervals $(95 \% \mathrm{CI})$ are presented to indicate the significance of association. Chi-square was calculated to test for a sex effect in cross-dominance. Finally, $t$ test was used to examine the differences of Purdue Pegboard performance between different eye-hand preference (crossed and consistent eye-hand dominance) groups.

\section{Results}

Results from bivariate analysis indicated that female schizophrenic patients, male schizophrenic patients, female controls and male controls were not significantly different in age or education (Table 1 ). There was no sex difference regarding age of onset or duration of schizophrenia in schizophrenic patients. The severity of psychopathology in patients with schizophrenia did not correlate significantly with patients' performance on the tests.

\section{Hand-preference Pattern}

On the Edinburgh Handedness Inventory, the schizophrenic group and the control group scored $85.3 \%$ and $79.7 \%$, respectively. No significant difference was found in the hand preference patterns between these two groups 
( $t=1.60$, ns). Furthermore, there was no significant difference in the handedness scores between male and female schizophrenic patients (male schizophrenic patients: score $=84.9, S D=20.0$; female schizophrenic patients: score $=85.8, S D=18.2 ; t=.66$, ns); see Table 1 .

\section{Eye-preference Pattern}

Because the number of left-handers, i.e., those with an Edinburgh Handedness score less than 0 was very small in both the schizophrenic group $(n=1)$ and the control group $(n=2)$, only right-handers were included in the analysis of differences in eye-preference pattern. Results from multivariate logistic regressions are shown in Table 2. Schizophrenic patients had significantly higher handedness mean $(\mathrm{OR}=1.01,95 \% \mathrm{CI}: 1.00-1.03, p<$ $.01)$ and were more likely to be left eyed or inconsistent $(\mathrm{OR}=4.75,95 \%$ CI: $2.22-10.12, p<.001)$ after controlling for sex, age and education. Furthermore, the tendency for increased cross dominance, i.e., right hand preference and left/inconsistent eye dominance, in schizophrenia was found in the female group $\left(80 \% ; \chi^{2}=11.25, p<.005\right)$ as well as the male group $\left(55.8 \% ; \chi^{2}=7.39, p<.01\right)$.

TABLE 2

Comparison of Schizophrenic Patients and Normal Controls in Clinical Characteristics

\begin{tabular}{|c|c|c|}
\hline & $\begin{array}{c}\text { Odds } \\
\text { Ratio }{ }_{\text {adjusted }}\end{array}$ & $95 \% \mathrm{CI}$ \\
\hline Sex (female) & 0.67 & $0.31,1.43$ \\
\hline Age & 0.97 & $0.93,1.02$ \\
\hline Education & 0.82 & $0.71,0.95 \dagger$ \\
\hline Handedness score & 1.01 & $1.00,1.03$ \\
\hline Eye dominance* & 4.75 & $2.22,10.12 \ddagger$ \\
\hline
\end{tabular}

*Left or inconsistent. $\dagger p<.01 . \neq p<.001$.

\section{Functional Significance of Eye-Hand Preference}

Data of Purdue Pegboard are only available for 50 schizophrenic patients and 30 healthy controls because the remaining subjects did not participate in the test due to time constraints. Comparison of demographic characteristics between the tested group (included in the analysis) and nontested group (excluded from the analysis) showed no significant difference. Results of $t$ test showed that the control group was more dexterous than the schizophrenic group (left hand: $F=27.03, p<.01$; right hand: $F=19.03, p<$ .01). The performance of participants on the Purdue Pegboard are shown in Table 3. In hand dexterity, the schizophrenic group showed no significant right-hand advantage compared to the control group. Schizophrenics with crossed eye-hand dominance performed significantly better with the right hand than with the left hand on the Purdue Pegboard (see Table 3). 
TABLE 3

Eye-Hand Preference (Crossed and Consistent Eye-Hand Dominance) in Relation to Purdue Pegboard Performance by Schizophrenic Patients and Normal Subjects

\begin{tabular}{|c|c|c|c|c|c|}
\hline \multirow{2}{*}{$\begin{array}{c}\text { Group and Eye-Hand } \\
\text { Dominance }\end{array}$} & \multirow[t]{2}{*}{$n$} & \multicolumn{2}{|c|}{ Purdue Pegboard } & \multirow[t]{2}{*}{$t$} & \multirow[t]{2}{*}{$p$} \\
\hline & & $\begin{array}{l}\text { Right } \\
\text { Hand }\end{array}$ & $\begin{array}{l}\text { Left } \\
\text { Hand }\end{array}$ & & \\
\hline \multicolumn{6}{|l|}{ Schizophrenic Group } \\
\hline Right/Dextral & 16 & 12.19 & 11.56 & 1.19 & ns \\
\hline Left or Inconsistent/Dextral & 34 & 12.38 & 11.00 & 3.86 & $<.005$ \\
\hline \multicolumn{6}{|l|}{ Control Group } \\
\hline Right/Dextral & 19 & 14.42 & 14.21 & .53 & ns \\
\hline Left or Inconsistent/Dextral & 11 & 15.00 & 14.36 & 1.55 & ns \\
\hline
\end{tabular}

\section{Discussion}

The findings are consistent with previous studies that report an increased incidence of left eye dominance in schizophrenia (Gur, 1977; Merrin, 1984; Yan, et al., 1985; Gureje, 1988; Cannon, et al., 1997). In a study of 70 schizophrenic patients, no sex difference was found in eye dominance (Oddy \& Lobstein, 1972). However, this study also found a higher ratio of nonright eye dominance in the female schizophrenics $(80 \%)$ than in the males $(50 \%)$. This result is similar to that of Yan, et al., 1985), who reported that left eye dominance tends to be more common in female schizophrenics $(33.7 \%)$ than others in a study that included only ethnic Chinese subjects. In general, decrements in the size of temporal lobe structures or the lobe itself and generally associated lateral cerebral ventricular enlargement are more prominent in schizophrenia (Leung \& Chue, 2000; Chua, Lam, Tai, Cheung, Tang, Chen, Lee, Chan, Lieh-Mak, \& McKenna, 2003). Leung and Chue (2000) suggested that the female brain is more symmetrically organized (less lateralized) than the male brain. Thus, if left hemisphere dysfunction is related to schizophrenia, then eye dominance is directly related to cerebral hemispheric dominance (Kameyama, et al., 1983), and females with schizophrenia might have a greater chance of showing left eye dominance.

Based on Edinburgh Handedness Inventory scores, schizophrenic patients in our study did not show a greater left-handed tendency when compared with healthy controls. This finding is not consistent with those of Western reports (Carlsson, et al., 1992; Orr, et al., 1999; Satz \& Green, 1999) but is consistent with a report based on a Chinese sample (Yan, et al., 1985). A model of handedness or lateralization incorporating both genetic and cultural processes has been proposed by Laland, Kumm, Van Horn, and Feldman (1995). Although no genetic variation may underlie variations in handedness, it is possible that variation in handedness or lateralization among humans may be the result of a combination of cultural and develop- 
mental factors (Mandal, Harizuka, Bhushan, \& Mishra, 2001; Li, Zhu, \& Nuttall, 2003). In Eastern societies, children are expected to perform daily activities using the right hand as the dominant side. This cultural pressure causes most individuals to grow up to be right-handed. Hence, the cultural factor may have contributed to the discrepancies in Western versus Eastern findings.

The clinical significance of hand-eye dominance in schizophrenic patients is not clear. With respect to how eye dominance may affect hand performance, results indicate that the individuals with crossed eye-hand dominance showed a tendency for better right hand than left hand performance on the Purdue Pegboard. Individuals with crossed eye-hand dominance may have poorer bilateral cerebral integration than those with consistent eyehand dominance. Therefore, those with a crossed dominance pattern may show a greater discrepancy between right and left hands in dexterity performance.

Results of this study must be interpreted with caution due to the following limitations. First of all, the power was low in all comparisons, ranging from .18 to .42 . Secondly, many confounding factors, such as obstetric complications, deviated sampling (all right handedness as in the current study), and used antipsychotics or other medications, are not adequately controlled. Thirdly, the design of the present study may not be sensitive enough to detect a large effect given the limited sample size. To study a small or moderate effect, one would need a larger sample to have significant findings (Rossi, 1997). Thus, further studies with a larger sample are needed. Finally, syndromatic characteristics may be important factors awaiting elucidation when addressing functional asymmetry in schizophrenia because researchers have argued that it is a heterogeneous syndrome (e.g., Ross, 2000). Gruzelier, Wilson, Liddiard, Peters, and Pusavat (1999) reported that schizophrenic patients with positive syndrome showed a right-sided impairment and negative syndrome showed a left-sided impairment. Further studies exploring the relationship between positive and negative symptoms of schizophrenia and eye and hand dominance are still needed. Additional research is also needed to investigate the effect of the eye/hand dominance pattern on tasks involving visual/manual control in individuals with schizophrenia.

\section{REFERENCES}

American Psychiatric Association. (1994) DSM-IV: diagnostic and statistical manual of mental disorders. (4th ed.) Washington, DC: American Psychiatric Association.

Cannon, M., Bryne, M., Cassidy, B., Larkin, C., Horgan, R., Sheppard, N. P., \& O’Callaghan, E. (1995) Prevalence and correlates of mixed-handedness in schizophrenia. Psychiatry Research, 59, 119-125.

Cannon, M., Jones, P., Murray, R. M., \& Wadsworth, M. E. (1997) Childhood laterality and later risk of schizophrenia in the 1946 British birth cohort. Schizopbrenia Research, 26, $117-120$.

Carlsson, C., Hugdahl, K., Uvebrant, P., Wiklund, L. M., \& Wendt, L. V. (1992) Pathologi- 
cal left-handedness revisited: dichotic listening in children with left vs right congenital hemiplegia. Neuropsychologia, 30, 471-481.

Chua, S. E., Lam, I. W. S., TaI, K-S., Cheung, C., Tang, W-N., Chen, E. Y. H., Lee, P. W. H., Chan, F-L., Lieh-MaK, F., \& McKenna, P. J. (2003) Brain morphological abnormality in schizophrenia is independent of country of origin. Acta Psychiatrica Scandinavica, 108, 269.

Crow, T. J. (1990) Temporal lobe asymmetries as the key to the etiology of schizophrenia. Schizophrenia Bulletin, 16, 433-443.

Crow, T. J., Colter, N., Frith, C. D., Johnstone, E. C., \& Owens, D. G. C. (1989) Developmental arrests of cerebral asymmetries in early onset schizophrenia. Psychiatry Research, $29,247-253$

DonNeluy, E. F. (1984) Neuropsychological impairment and associated intellectual functions in schizophrenic and other psychiatric patients. Biological Psychiatry, 19, 815-824.

Gruzelier, J. H., Wilson, L., Liddiard, D., Peters, E., \& Pusavat, L. (1999) Cognitive asymmetry patterns in schizophrenia: active and withdrawn syndromes and sex differences as moderators. Schizophrenia Bulletin, 25, 349-362.

GuR, R. E. (1977) Motoric laterality imbalance in schizophrenia: a possible concomitant of left hemisphere dysfunction. Archives of General Psychiatry, 34, 33-37.

Gureje, O. (1988) Sensorimotor laterality in schizophrenia: which features transcend cultural influences? Acta Psychiatrica Scandinavica, 77, 188-193.

Kameyama, T., Niwa, S. I., Hiramatsu, S. I., \& Saitoh, O. (1983) Hand preference and eye dominance patterns in Japanese schizophrenics. In P. Flor-Henry \& J. H. Gruzelier (Eds.), Laterality and psychopathology. Amsterdam: Elsevier. Pp. 181-194.

Laland, K. N., Kumm, J., Van Horn, J. D., \& Feldman, M. W. (1995) A gene-culture model of human handedness. Behavior Genetics, 25, 433-445.

Leung, A., \& Chue, P. (2000) Sex differences in schizophrenia: a review of the literature. Acta Psychiatrica Scandinavica, 101, 3-38.

Li, C., Zhu, W., \& NutTall, R. L. (2003) Familial handedness and spatial ability: a study with Chinese students aged 14-24. Brain and Cognition, 51, 375-384.

Lobel, D. S., Swanda, R. M., \& Losonczy, M. F. (1994) Lateralized visual-field inattention in schizophrenia. Perceptual and Motor Skills, 79, 699-702.

Mandal, M. K., Harizuka, S., Bhushan, B., \& Mishra, R. C. (2001) Cultural variation in hemifacial asymmetry of emotion expressions. British Journal of Social Psychology, 40, 385-398.

Merrin, E. (1984) Motor and sighting dominance in schizophrenia and affective disorder. British Journal of Psychiatry, 146, 539-544.

Oddy, H. C., \& Lobstein, T. J. (1972) Hand and eye dominance in schizophrenia. British Journal of Psychiatry, 120, 331-332.

Oldfield, R. C. (1971) The assessment and analysis of handedness: the Edinburgh inventory. Neuropsychologia, 9, 97-113.

Orr, K. G. D., Cannon, M., Gilvarry, C. M., Jones, P. B., \& Murray, R. M. (1999) Schizophrenic patients and their first-degree relatives show an excess of mixed-handedness. Schizopbrenia Research, 39, 167-176.

Overall, J. E., \& Gorham, D. R. (1962) The Brief Psychiatric Rating Scale. Psychological Reports, 10, 799-812.

Piran, N., Bigler, E. D., \& Cohen, D. (1982) Motoric laterality and eye dominance suggest unique pattern of cerebral organization in schizophrenia. Archives of General Psychiatry, 39, 1006-1010.

Porac, C., \& Coren, S. (1976) The dominant eye. Psychological Bulletin, 83, 880-897.

Robison, S. E., Block, S. S., Boudreaux, J. D., \& Flora, R. J. (1999) Hand-eye dominance in population with mental handicaps: prevalence and a comparison of methods. Journal of the American Optometric Association, 70, 563-570.

Ross, E. R. (2000) The deficit syndrome and eye tracking disorder may reflect a distinct subtype within the syndrome of schizophrenia. Schizophrenia Bulletin, 26, 855-866.

Rossi, A. (1997) A case study in the failure of psychology as a cumulative science: the spontaneous recovery of verbal learning. In L. L. Harlow, S. A. Mulaik, \& J. H. Steiger (Eds.), What if there were no significance tests? Mahwah, NJ: Erlbaum. Pp. 175-198. 
SATZ, P., \& GreEn, M. F. (1999) Atypical handedness in schizophrenia: some methodological and theoretical issues. Schizophrenia Bulletin, 25, 63-78.

Sheehan, D. V., Lecrubier, Y., Sheehan, K. H., Amorim, P., Janavs, J., Weiller, E., Hergueta, T., Baker, R., \& Dunbar, G. C. (1998) The Mini-International Neuropsychiatric Interview (M.I.N.I.): the development and validation of a structured diagnostic psychiatric interview for DSM-IV and ICD-10. Journal of Clinical Psychiatry, 59, 22-33.

Tiffin, J., \&Asher, E. J. (1948) The Purdue Pegboard: norms and studies of reliability and validity. Journal of Applied Psychology, 32, 234-247.

Yan, S. M., Flor-Henry, P., Chen, D. Y., Li, T. G., QI, S. G., \& MA, Z. X. (1985) Imbalance of hemispheric functions in the major psychoses: a study of handedness in the People's Republic of China. Biological Psychiatry, 20, 906-917.

Accepted April 12, 2004. 
